\title{
Bamboo spine - X-ray findings of ankylosing spondylitis revisited
}

\author{
Antoinette Reinders, $M B C h B$ \\ Matthys J van Wyk, MB ChB, FCRad Diag (SA) \\ Department of Diagnostic and Interventional Radiology, University of the Free State, Bloemfontein
}

Corresponding author: A Reinders (antoinette.reinders@gmail.com)

\begin{abstract}
Ankylosing spondylitis is a debilitating disease that is one of the seronegative spondylarthropathies, affecting more males than females in the proportion of about 6:1 in the age group 15 - 35 years of age. Early radiographic findings include bilateral sacro-iliitis and early axial (lower lumbar spine) ankylosis. Typical X-ray findings are florid spondylitis (Romanus lesions), florid diskitis (Andersson lesions), early axial ankylosis, enthesitis, syndesmophytes and insufficiency fractures. Typical radiological abnormalities are pointed out on conventional X-rays and reviewed for early diagnosis and prompt treatment of patients at risk.
\end{abstract}

S Afr J Rad 2012;16(3):111-113. DOI:10.7196/SAJR.684

Ankylosing spondylitis (AS) is one of the sero-negative spondyloarthropathies. ${ }^{1}$ This group of arthritides is characterised by specific skeletal imaging findings and, biochemically, by the absence of rheumatoid factor or nodules, and the presence of the HLA-B27 gene. These spondylo-arthropathies can be divided into 5 major groups: (i) ankylosing spondylitis, (ii) reactive arthritis/Reiter's syndrome, (iii) arthritis associated with inflammatory bowel disease, (iv) psoriatic arthritis and $(v)$ undifferentiated spondylo-arthropathy. ${ }^{1}$

AS is a debilitating disease, affecting mostly white men, with a male:female ratio of about 6:1 within the age group 15 - 35 years of age. Early lumbar axial ankylosis and spinal involvement is more marked in male patients than female, with early radiographic signs of hip

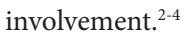

Classic joint involvement includes: bilateral sacro-iliac, thoracolumbar and lumbo-sacral joints (early) and cervical spine (late). ${ }^{5}$ The peripheral skeleton is involved in $10-20 \%$ of cases, with apical fibrosis of the lung parenchyma reported in only $1 \%$ of AS patients. ${ }^{6}$ Additional cardiac manifestations, such as aortic valve and root abnormalities, and with conduction and rhythm abnormalities, have also been reported in 2 - $10 \%$ of patients. ${ }^{6}$

Genetic susceptibility has been mentioned as a causative factor, with $96 \%$ of patients testing positive for the HLA-B27 gene. ${ }^{1}$ Associated diseases include: ulcerative colitis, iritis and aortic insufficiency. Prognosis depends on age at first presentation, as well as the radiological grade, as defined by either the Bath Ankylosing Spondylitis Radiology Index (BASRI) - for cervical and lumbar spine and hips - or the Modified New York Criteria for the Extent of Sacro-iliitis, with lumbar and bilateral sacro-iliac joint involvement being marked in the early years of the disease. ${ }^{6}$

\section{Pathology and imaging characteris- tics}

In this pictorial essay, we focus on the characteristic axial skeleton imaging findings of AS, as it presents on conventional X-ray: ${ }^{1}$

- $\quad$ florid anterior spondylitis (Romanus lesions)

- florid diskitis (Andersson lesions)

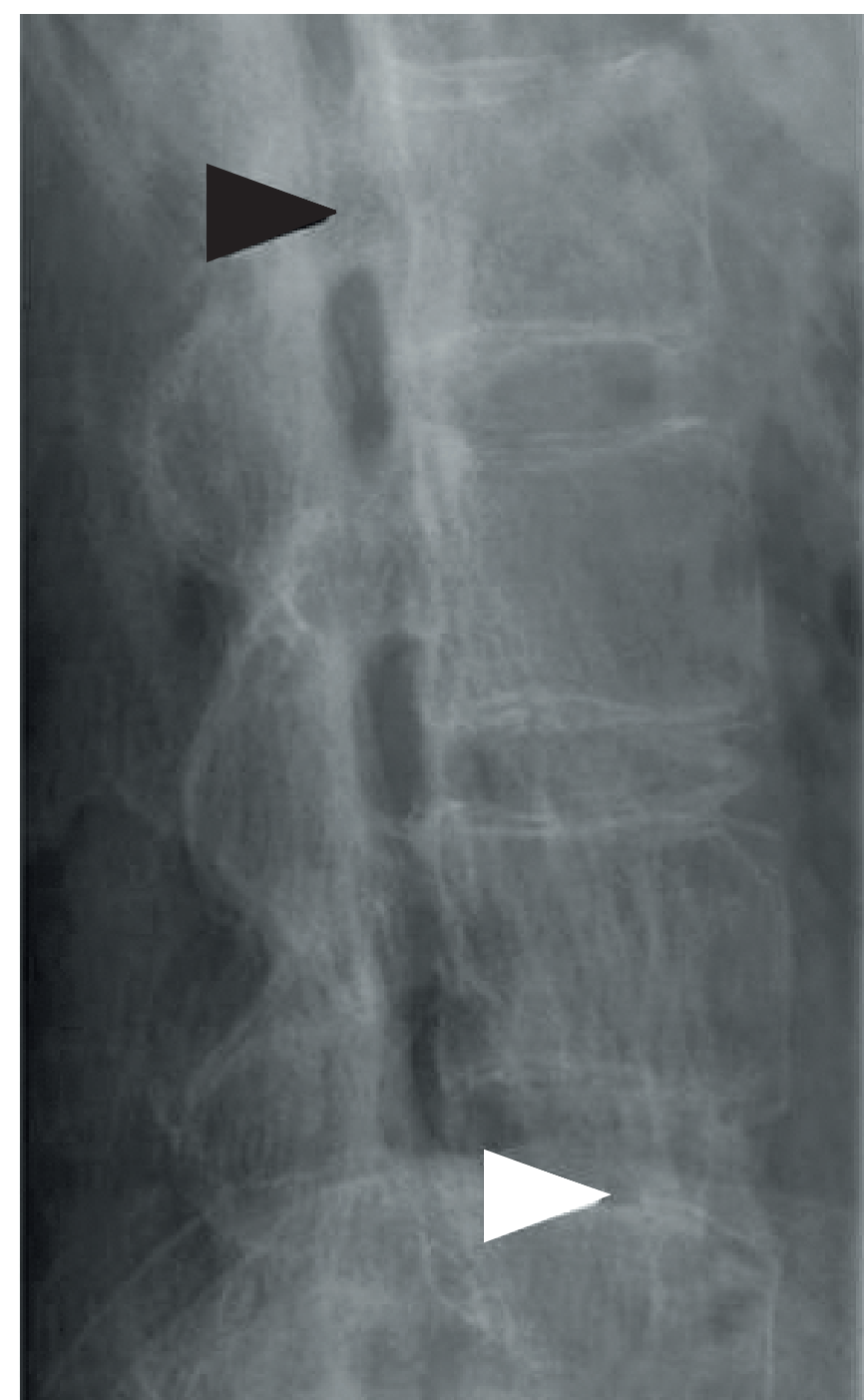

Fig 1. Lateral lumbar spine view. Note the 'squaring' of the lumbar vertebrae (open arrowhead), together with the central radio-dense region in the vertebral endplate of the 5th lumbar vertebra, superiorly (white arrowhead). This is known as an Andersson lesion. 


\section{PICTORIAL ESSAY}

- insufficiency fractures of the ankylosed spine

- $\quad$ syndesmophytes

- $\quad$ enthesitis of the interspinal ligaments

- ankylosis

\section{Romanus lesions (florid anterior spondylitis)}

It is best to describe these lesions in terms of a disco-vertebral unit (DVU). This 'unit' comprises the superior half of the inferior vertebrae, plus the intervertebral disc, plus the inferior half of the superior vertebrae. ${ }^{1}$ Typical Romanus lesions are situated at the attachment of the annulus fibrosis to the vertebral endplate, and can be in the anterior, posterior or marginal regions of the DVU. Irregularities and erosions of the vertebral endplates are characteristic of acute inflammation. Post-inflammatory changes are known as 'shiny corners', which appear as sclerotic lesions in the same anatomical location on the vertebral endplate. ${ }^{1}$ When these lesions are present, 'squaring' of the vertebrae can be appreciated, with progressive loss of the lumbar lordosis (Fig. 1).

\section{Andersson lesions (florid diskitis)}

These appear as irregularities and erosions of the vertebral endplates (Fig. 1), not related to the anterior or posterior edge but rather to the central portions of the intervertebral discs. These are better visualised by MR images of the spine, but can be seen on conventional X-ray and are indicative of active inflammation.

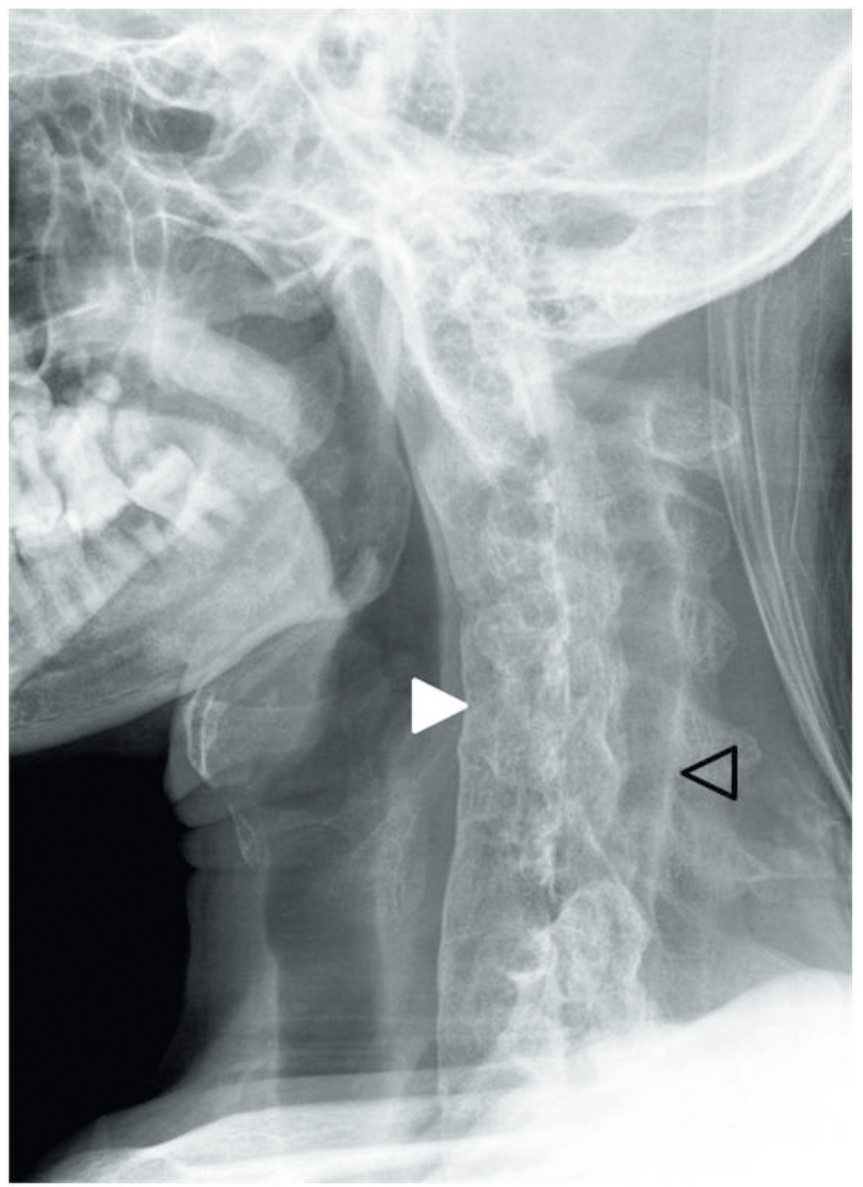

Fig. 2. Lateral cervical spine X-ray. The white arrowhead indicates syndesmophytes, representing calcification of the anterior portion of the annulus fibrosis. Calcification of the interspinous ligaments can also be seen (open arrowhead).

\section{Insufficiency fractures}

These can be referred to as 'non inflammatory Andersson lesions' and are a not uncommon complication of advanced disease. ${ }^{1}$ They can be classified into 2 basic categories: (i) spontaneous or (ii) following minimal trauma. ${ }^{7}$ The fractures are typically 3-column, involving either the disc space or juxta-articular endplate. The second category typically occur near the cervico-thoracic or thoraco-lumbar junctions. Delay in treatment can cause pseudoarthrosis, which can be seen on conventional X-rays as subchondral sclerosis and vertebral endplate erosions. ${ }^{7}$

\section{Syndesmosphytes}

These are paravertebral ossifications that resemble an osteophyte, but run in the vertical rather than the horizontal plane (Fig. 2). ${ }^{8}$ They are not due to calcification of the anterior longitudinal ligament but rather ossification of the anterior portion of the annulus fibrosis of the intervertebral disc. The lesions are preceded by a Romanus lesion, and are symmetrical and marginal. About 15\% of affected patients show evidence of syndesmophytes.

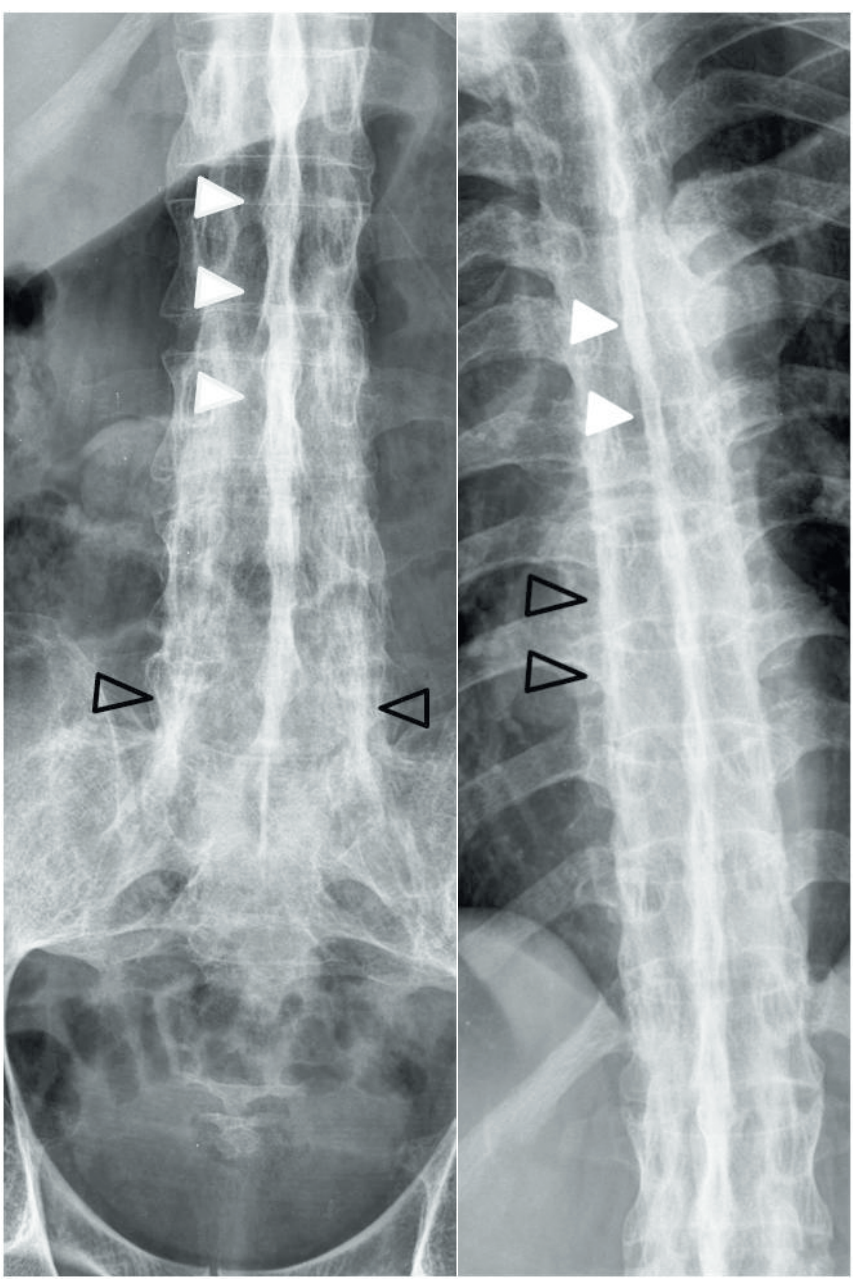

Fig. 3. Antero-posterior view of the thoracic and lumbar spine. Note the calcification of the interspinous ligaments secondary to enthesitis, with the classic dagger sign (white arrowheads) stretching into the pelvis. The trolley track sign can also be seen in the lower lumbar spine and thoracic spine (open arrowheads), lateral to the calcified interspinous ligaments, representing the calcified apophyseal joint capsules. 


\section{PICTORIAL ESSAY}

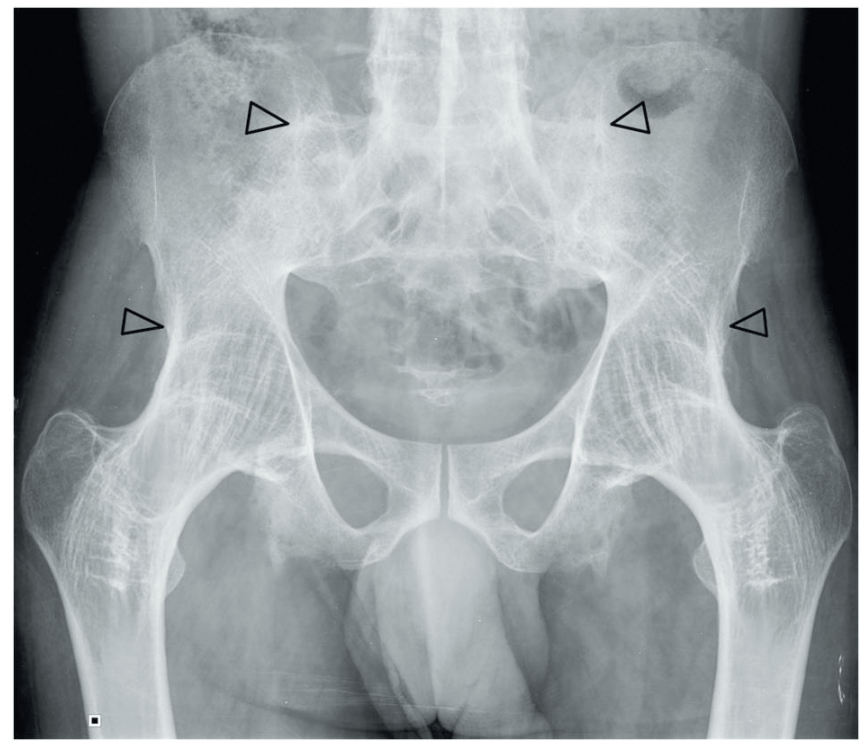

Fig. 4. Antero-posterior view of the pelvis. The open arrowheads indicate marked ankylosis of the hips and sacro-iliac joints.

\section{Enthesitis (trolley track and dagger signs) ${ }^{9}$}

Ossification of the supraspinous and interspinous ligaments produces a characteristic single or double radio-dense sign on the AP view of the spine (Fig. 3). The trolley track sign derives from the 2 lateral lines of ossification representing the apophyseal joint capsules, and the dagger sign from the central line of ossification visible on the AP view. Enthesitis precedes ossification of the ligaments. ${ }^{9}$

\section{Ankylosis}

Ankylosis of several of the joints causes structural abnormalities of the axial skeleton. Marked ankylosis is seen at the sacro-iliac joints (Fig. 4) and facet joints of the thoracic spine, and costovertebral and costotransverse joints ${ }^{1}$ that causes an exaggerated kyphosis with decreased chest expansion during inhalation and increased susceptibility to respiratory tract infections.

\section{Conclusion}

AS is a debilitating disease with very specific radiological abnormalities that can, if detected early, be successfully managed by medical and physical therapy. It remains the role of the radiologist to keep a look-out for early radiological abnormalities in susceptible patients.

1. Hermann KGA, Althoff $\mathrm{CE}$, Schneider U, et al. Spinal changes in patients with spondylarthritis: Comparison of MR imaging and radiographic appearances. RadioGraphics 2005;25:559-570.

2. Boonen A, Van der Cruyssen B, de Vlam K, et al. Spinal radiographic changes in ankylosing spondylitis: association with clinical characteristics and functional outcome. J Rheumatol 2009;36(6):1249-1255.

3. Atagunduz P, Aydin SZ, Bahadir C, et al. Determinants of early radiographic progression in ankylosing spondylitis. J Rheumatol 2010;37(11):2356-2361.

4. Cansu DU, Calisir C, Savas Yavas U, et al. Predictors of radiographic severity and functional disability in turkish patients with ankylosing spondylitis. Clin Rheumatol 2011;30(4):557-562.

5. Jang HJ, Ward MM, Rucker AN, et al. Ankylosing spondylitis: Patterns of radiographic involvement - a re-examination of accepted principles in a cohort of 769 patients. Radiology 2011;258(1):192-198.

6. Momeni M, Taylor N, Tehrani M, et al. Cardiopulmonary manifestations of ankylosing spondylitis. Int J Rheumatol 2011;1:1-6.

7. Hong SH, Ja-Young C, Joon Woo L, et al. MR imaging assessment of the spine: infection or an imitation? RadioGraphics 2009;29:599-612.

8. Helms CA. Arthritis. In: Brant WE, Helms CA, eds. Fundamentals of Diagnostic Radiology. 3rd ed. Philadelphia: Lippincott Williams \& Wilkins, 2007:1136-1140.

9. Olivieri I, Ciancio G, Scarano E, et al. The extension of the ankylosing spondylitis "dagger sign" into the sacrum. J Rheumatol 2000;27(12):2944-2945. 